\title{
Raman Spectroscopy of Nickel Sulfide $\mathrm{Ni}_{3} \mathrm{~S}_{2}$
}

\author{
Zhe Cheng, Harry Abernathy, and Meilin Liu* \\ School of Materials Science and Engineering, Georgia Institute of Technology, 771 Ferst Drive NW, \\ Atlanta, Georgia 30332
}

Received: August 31, 2007; In Final Form: October 25, 2007

\begin{abstract}
Raman spectra of nickel sulfides reported in previous studies are inconsistent due possibly to the difficulty in obtaining samples of the required purity in composition and phase. In this study, Raman spectra for both the low-temperature (heazlewoodite)- and the high-temperature (cubic)-phase $\mathrm{Ni}_{3} \mathrm{~S}_{2}$, collected under both ex situ and in situ conditions, are correlated with factor group analysis and X-ray diffraction. The study is important to the investigation of sulfur-nickel interactions in catalyst systems for processing of sulfur-containing chemicals and in solid oxide fuel cells (SOFCs) that run on sulfur-containing fuels; it also provides a standard reference for research in areas such as the corrosion of nickel-based alloys in a sulfur-containing atmosphere.
\end{abstract}

\section{Introduction}

In the study of gas/electrode interactions for solid oxide fuel cells (SOFCs), Raman spectroscopy is an effective tool in the detection of species formed on the electrode surface, especially under in situ conditions (i.e., at high temperature in a certain gas atmosphere). ${ }^{1-3}$ For nickel, the catalyst material for SOFC anodes, however, the problem of detecting and identifying surface sulfide species can be complicated because nickel sulfides have many different structures with different stoichiometries. Further, not all of the Raman spectra for the reported sulfides have been determined unambiguously. For example, $\mathrm{Ni}_{3} \mathrm{~S}_{2}$, which commonly exists as the mineral heazlewoodite and is a typical corrosion product for nickel, has a rhombohedral structure with a space group of $R 32$ (see JCPDS card No. 441418). The reported Raman spectra for the heazlewoodite-phase $\mathrm{Ni}_{3} \mathrm{~S}_{2}$ conflict with each other. ${ }^{4-7}$ In addition, the Raman spectrum for the high-temperature cubic-phase $\mathrm{Ni}_{3} \mathrm{~S}_{2}$ has never been reported.

During the study of the sulfur-anode interactions in solid oxide fuel cells, we measured the Raman spectra for both the low-temperature (heazlewoodite)- and the high-temperaturephase $\mathrm{Ni}_{3} \mathrm{~S}_{2}$ using in situ Raman spectroscopy. The results shown were correlated with factor group analysis, confirmed with X-ray diffraction (XRD), and compared with previous studies. These results provide a standard reference for the Raman spectra of $\mathrm{Ni}_{3} \mathrm{~S}_{2}$, important for studying the interactions between sulfur and nickel (or nickel-based alloys) in a sulfur-containing atmosphere.

\section{Experimental Procedures}

The samples used in this study were dense composite pellets containing 40 vol \% nickel and 60 vol \% yttria-stabilized zirconia (YSZ). A nickel-YSZ composite was used because the study was carried out in the process of investigating the

* To whom correspondence should be addressed. E-mail: meilin.liu@ mse.gatech.edu. Tel.: +1-404-894-6114. interactions of sulfur with a typical Ni-YSZ SOFC anode. The individual nickel grain sizes were on the order of $\sim 20-60 \mu \mathrm{m}$. Since the Raman laser sample spot was focused to an intense spot of $\sim 1 \mu \mathrm{m}$ diameter, this grain size allowed for the Raman measurement of the sulfide phase formed on the nickel surface without any interference from the neighboring YSZ phase. Raman spectra were collected using a Renishaw RM 1000 Raman microscope. The objective had a $50 \times$ magnification. The laser wavelength was usually $514 \mathrm{~nm}$ (Ar ion laser, Melles Griot), and the power of the laser beam at the focal point was $\sim 1 \mathrm{~mW}$. For the in situ Raman experiment, a Ni-YSZ composite pellet, with a polished surface, was mounted onto the sample stage of a customized Raman sample chamber (modified HVC-DRP-1, Harrick Scientific) using a gold paste (C5755A, Heraeus). The Raman chamber was then heated in flowing hydrogen to the measuring temperature. $\mathrm{Ni}_{3} \mathrm{~S}_{2}$ was formed in situ by exposing the $\mathrm{Ni}-\mathrm{YSZ}$ composite to a flowing $\mathrm{H}_{2} \mathrm{~S} / \mathrm{H}_{2}$ fuel mixture with $p\left(\mathrm{H}_{2} \mathrm{~S}\right) / p\left(\mathrm{H}_{2}\right)=10^{-4}(100 \mathrm{ppm})$ at $\sim 440{ }^{\circ} \mathrm{C}$ (the symbol " $\sim$ " is used since the error for temperature measurement was $\pm 5^{\circ} \mathrm{C}$ ). The Raman spectra, as well as optical images showing surface morphology, were recorded before and after $100 \mathrm{ppm} \mathrm{H}_{2} \mathrm{~S}$ was introduced into the Raman chamber. To characterize $\mathrm{Ni}_{3} \mathrm{~S}_{2}$ at temperatures greater than $\sim 440{ }^{\circ} \mathrm{C}$ using in situ Raman, a compact of commercial $\mathrm{Ni}_{3} \mathrm{~S}_{2}$ (Aldrich \#343226, which was actually a mixture of $\mathrm{Ni}_{3} \mathrm{~S}_{2}$ and $\mathrm{Ni}_{7} \mathrm{~S}_{6}$, as determined by XRD) was placed on a YSZ pellet placed on the sample cup. The sample was heated in a flowing fuel mixture of $50 \mathrm{ppm} \mathrm{H}_{2} \mathrm{~S} / 50 \% \mathrm{H}_{2} / 50 \% \mathrm{~N}_{2}$ (by volume) to an elevated temperature up to $\sim 580{ }^{\circ} \mathrm{C}$. (The phase transition between the low-temperature heazlewoodite-phase $\mathrm{Ni}_{3} \mathrm{~S}_{2}$ and the hightemperature cubic-phase $\mathrm{Ni}_{3} \mathrm{~S}_{2}$ happens at $565 \pm 5^{\circ} \mathrm{C}$.) $\mathrm{X}$-ray diffraction (XRD) was carried out using a PW1800 X-ray diffractometer (Philips Analytical) at room temperature in air using $\mathrm{Cu} \mathrm{K} \alpha$ radiation.

\section{Results and Discussion}

Figure 1 shows the XRD pattern of the $\mathrm{Ni}-\mathrm{YSZ}$ composite sample after being exposed to a flowing gas mixture of 100 


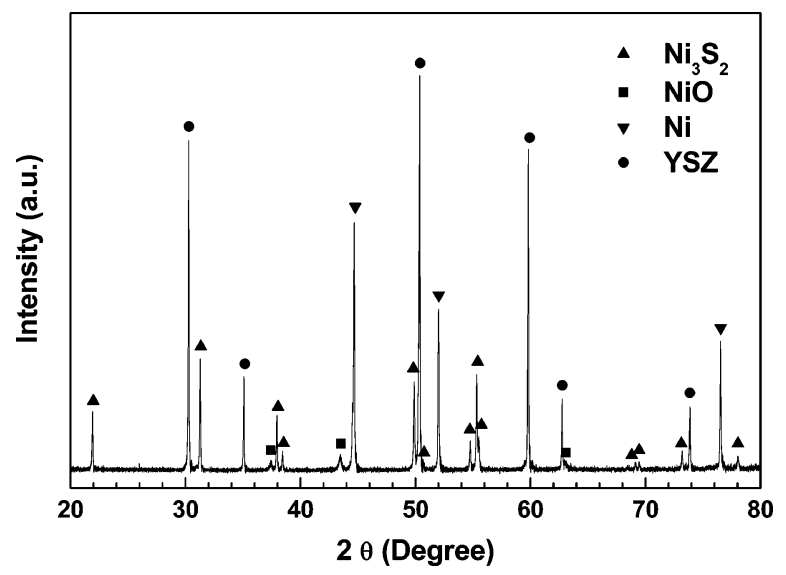

Figure 1. XRD pattern of the Ni-YSZ composite after exposure to $100 \mathrm{ppm} \mathrm{H}_{2} \mathrm{~S} / \mathrm{H}_{2}$ at $\sim 440{ }^{\circ} \mathrm{C}$ for $12 \mathrm{~h}$ and quickly cooled to room temperature.

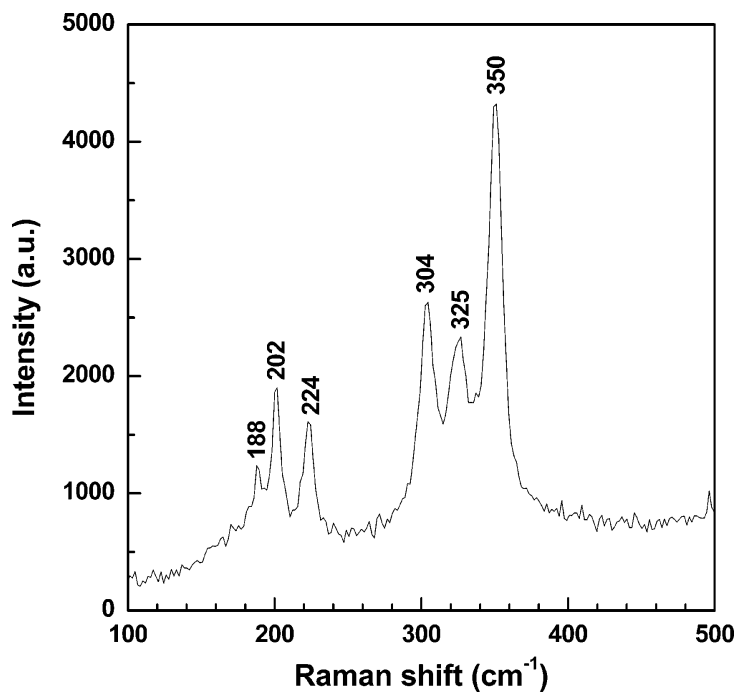

Figure 2. Room-temperature Raman spectrum of $\mathrm{Ni}_{3} \mathrm{~S}_{2}$ formed on a $\mathrm{Ni}$ surface after exposure to $100 \mathrm{ppm} \mathrm{H}_{2} \mathrm{~S} / \mathrm{H}_{2}$ at $\sim 440{ }^{\circ} \mathrm{C}$ for $12 \mathrm{~h}$.

ppm $\mathrm{H}_{2} \mathrm{~S} / \mathrm{H}_{2}$ at $\sim 440{ }^{\circ} \mathrm{C}$ for $12 \mathrm{~h}$ and then quickly cooled to room temperature in a gas mixture of $4 \% \mathrm{H}_{2} / 96 \% \mathrm{Ar}$ at a rate of $\sim 70{ }^{\circ} \mathrm{C} / \mathrm{min}$. In addition to $\mathrm{Ni}$ and $\mathrm{YSZ}$, which are the major components of the composite, $\mathrm{Ni}_{3} \mathrm{~S}_{2}$ (heazlewoodite phase) and trace amounts of $\mathrm{NiO}$ were detected. The thickness of the $\mathrm{Ni}_{3} \mathrm{~S}_{2}$ layer was estimated to be $\sim 1-5 \mu \mathrm{m}$ from the roughness of the nickel surface. Figure 2 shows the corresponding roomtemperature Raman spectrum taken from the Ni regions, whose surface was covered by $\mathrm{Ni}_{3} \mathrm{~S}_{2}$ and trace amounts of $\mathrm{NiO}$. The spectrum has a total of six peaks at 188, 202, 224, 304, 325, and $350 \mathrm{~cm}^{-1}$. The Raman spectrum remained the same when the laser wavelength was changed from 514 to $488 \mathrm{~nm}$. This spectrum is believed to correspond to heazlewoodite-phase $\mathrm{Ni}_{3} \mathrm{~S}_{2}$ for several reasons. First, factor group analysis based on the correlation method given by Fateley et al. ${ }^{8}$ shows that the irreducible representation $\Gamma$ of the phonon modes for the heazlewoodite-phase $\mathrm{Ni}_{3} \mathrm{~S}_{2}$ (space group $R 32(155)$ or $D_{3}^{7}$ ) is

$$
\Gamma_{\mathrm{vib}}^{\mathrm{Ni}_{3} \mathrm{~S}_{2}, \text { crystal }}=2 \mathrm{~A}_{1}^{\mathrm{R}}+2 \mathrm{~A}_{2}^{\mathrm{IR}}+4 \mathrm{E}^{\mathrm{R}, \mathrm{IR}}
$$

of which there are a total of six Raman-active bands, two $\mathrm{A}_{1}$ and four E. Second, the cubic NiO phase identified by XRD has a space group of $F m 3 m(225)$ or $O_{h}^{5}$, for which $\Gamma_{\text {vib }}^{\mathrm{NiO}, \text { crystal }}=$ $\mathrm{F}_{1 \mathrm{u}}^{\mathrm{IR}}$, which is not Raman active. In fact, previous studies revealed no sharp features in the $150-400 \mathrm{~cm}^{-1}$ region of the

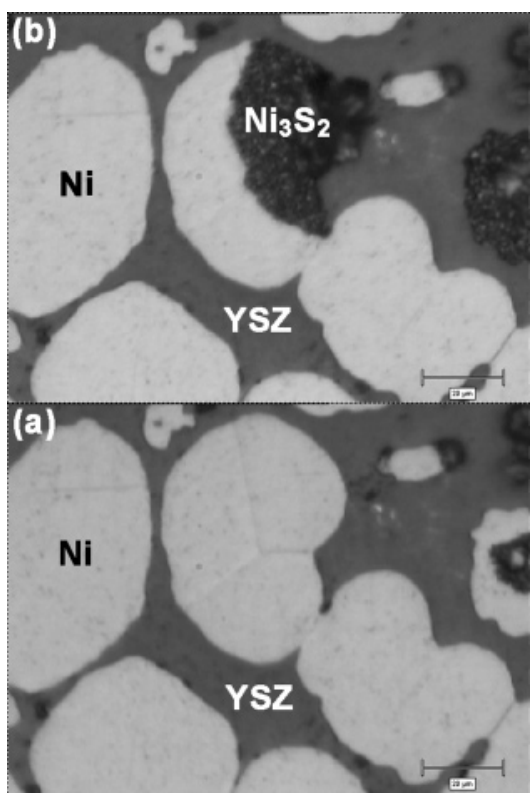

Figure 3. Optical microscopy images of the $\mathrm{Ni}-\mathrm{YSZ}$ composite before (a) and after (b) the formation of $\mathrm{Ni}_{3} \mathrm{~S}_{2}$ on the Ni surface when it was exposed to a fuel of $100 \mathrm{ppm} \mathrm{H}_{2} \mathrm{~S} / \mathrm{H}_{2}$ at $\sim 440{ }^{\circ} \mathrm{C}$ for $12 \mathrm{~h}$. The micron bar represents $20 \mu \mathrm{m}$.

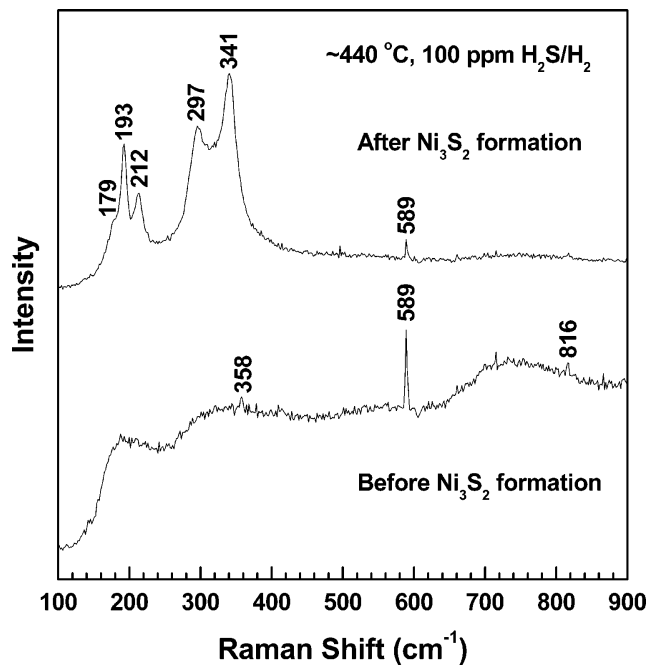

Figure 4. Raman spectra taken from the Ni region before and after the formation of $\mathrm{Ni}_{3} \mathrm{~S}_{2}$ during the in situ experiment at $\sim 440{ }^{\circ} \mathrm{C}$ in a fuel gas of $100 \mathrm{ppm} \mathrm{H}_{2} \mathrm{~S} / \mathrm{H}_{2}$.

Raman spectrum for $\mathrm{NiO}$ powders., ${ }^{9,10}$ The third piece of evidence can be seen in the in situ Raman data, which traced the formation of $\mathrm{Ni}_{3} \mathrm{~S}_{2}$ on the $\mathrm{Ni}-\mathrm{YSZ}$ composite surface at elevated temperatures in $\mathrm{H}_{2} \mathrm{~S}$-containing fuels. According to the phase diagram constructed by Rosenqvist and the thermal chemical data in the literature, ${ }^{11,12} \mathrm{Ni}_{3} \mathrm{~S}_{2}$ forms at $\sim 440{ }^{\circ} \mathrm{C}$ or below in gas mixtures with $p\left(\mathrm{H}_{2} \mathrm{~S}\right) / p\left(\mathrm{H}_{2}\right)=10^{-4}$. On the basis of those reported results, we carried out our in situ Raman experiment at $\sim 440{ }^{\circ} \mathrm{C}$ in a fuel mixture of $100 \mathrm{ppm} \mathrm{H}_{2} \mathrm{~S} / \mathrm{H}_{2}$. (We did not use a lower temperature in the range of $\sim 300-$ $400{ }^{\circ} \mathrm{C}$ because (i) the reaction kinetics would be slower and (ii) other nickel sulfides such as $\mathrm{Ni}_{7} \mathrm{~S}_{6}$ or $\mathrm{NiS}$ would start to form in the same fuel at lower temperatures.) Figure 3 shows the change in the optical microscopy image of the Ni surface before and after $\mathrm{Ni}_{3} \mathrm{~S}_{2}$ formation, while Figure 4 shows the corresponding change in the Raman spectrum taken from the same Ni region. The relative position and intensity of those peaks match those obtained at room temperature very well, except that every peak shifted to a lower wavenumber. For 
example, the peak at $350 \mathrm{~cm}^{-1}$ shifted to $341 \mathrm{~cm}^{-1}$ as the sample temperature increased from 20 to $\sim 440{ }^{\circ} \mathrm{C}$, which was expected from the thermal expansion of the lattice. ${ }^{13}$ The peak at $\sim 325$ $\mathrm{cm}^{-1}$ in Figure 2 is not visible probably because it is buried by the two adjacent peaks. The sharp peaks at 358, 589, and 816 $\mathrm{cm}^{-1}$ in those spectra are due to the rotation of physically adsorbed hydrogen. ${ }^{14}$ In addition to the experimental evidence provided above, the Raman spectrum for $\mathrm{Ni}_{3} \mathrm{~S}_{2}$ has been confirmed by ab initio calculations, which provided assignment of the Raman bands. ${ }^{13}$ All of these results lead to the conclusion that the Raman spectrum shown in Figure 2 indeed corresponds to the heazlewoodite-phase $\mathrm{Ni}_{3} \mathrm{~S}_{2}$.

The spectrum obtained here for the heazlewoodite phase is different from most previous results in the literature. ${ }^{4-7}$ Ozkan et al. reported that their self-made $\mathrm{Ni}_{3} \mathrm{~S}_{2}$ sample did not show any Raman bands. ${ }^{4}$ Zhu et al. claimed that $\mathrm{Ni}_{3} \mathrm{~S}_{2}$ has one characteristic peak at $115 \mathrm{~cm}^{-1} .5$ Bishop reported that $\mathrm{Ni}_{3} \mathrm{~S}_{2}$ (high-purity heazlewoodite, $97.98 \%$, Aldrich Chemical Co.) has a total of 10 Raman peaks. ${ }^{6}$ Earlier, our own group, we now believe, incorrectly attributed Raman spectra with peaks at 208, 288 , and $334 \mathrm{~cm}^{-1}$ to $\mathrm{Ni}_{3} \mathrm{~S}_{2} \cdot{ }^{15,16}$ The only match in the literature is the spectrum obtained using a $532 \mathrm{~nm}$ laser in the RRUFF database of Raman spectra, X-ray diffraction and chemistry data for minerals by the University of Arizona. ${ }^{7}$ It is not clear, however, why the researchers constructing the database obtained a quite different spectrum when using a $785 \mathrm{~nm}$ laser. Nevertheless, the huge discrepancy for the Raman spectrum of heazlewoodite-phase $\mathrm{Ni}_{3} \mathrm{~S}_{2}$ in the literature illustrates the difficulty in obtaining high-purity $\mathrm{Ni}_{3} \mathrm{~S}_{2}$ with the right phase by conventional methods. The nickel-sulfur system is very complicated, with several compounds existing. ${ }^{11,17-20}$ It is possible that the surface of the samples used by some other researchers did not have the exact stoichiometry and/or structure. Further, the surface of the sulfide sample may have been oxidized to $\mathrm{NiO}$. In fact, as stated earlier, even the commercial $\mathrm{Ni}_{3} \mathrm{~S}_{2}$ purchased from Aldrich by the authors turned out to be a mixture of $\mathrm{Ni}_{3} \mathrm{~S}_{2}$ and $\mathrm{Ni}_{7} \mathrm{~S}_{6}$. The Raman spectra obtained from some regions of the Aldrich " $\mathrm{Ni}_{3} \mathrm{~S}_{2}$ " are the same as that shown in Figure 2, but from some other regions, the spectra either contain a wide band in the range of 280 to $380 \mathrm{~cm}^{-1}$ (probably corresponding to $\mathrm{Ni}_{7} \mathrm{~S}_{6}$ ) or resemble the spectrum of $\mathrm{NiO}$. Such problems are solved by using an in situ setup that enables Raman measurement of the sample in a controlled environment after hours of exposure, ensuring the formation of the right phase desired from the phase diagram. ${ }^{11}$

According to the literature, $\mathrm{Ni}_{3} \mathrm{~S}_{2}$ will go through a phase change from the low-temperature rhombohedral structure (heazlewoodite) to the high-temperature cubic structure at $565 \pm$ $5^{\circ}$ C. ${ }^{11,17-20}$ The Raman spectrum for the high-temperature cubicphase $\mathrm{Ni}_{3} \mathrm{~S}_{2}$ has never been reported. In this study, the Raman spectroscopy for $\mathrm{Ni}_{3} \mathrm{~S}_{2}$ at elevated temperatures was also investigated. The Raman spectra obtained near the phase transition temperature for $\mathrm{Ni}_{3} \mathrm{~S}_{2}$ are shown in Figure 5. At temperatures below $\sim 563{ }^{\circ} \mathrm{C}$, the Raman spectra were similar to those at room temperature (Figures 2 and 4), except most peaks shifted to a lower wavenumber. Once the temperature increased to $\sim 567^{\circ} \mathrm{C}$, the Raman peaks at 186, 205, 294, and $334 \mathrm{~cm}^{-1}$ disappeared suddenly; they reappeared when the temperature was reduced to $\sim 556{ }^{\circ} \mathrm{C}$.

According to JCPDS card No. 27-0341, the high-temperature form of $\mathrm{Ni}_{3} \mathrm{~S}_{2}$ has a space group of $\bar{F} \overline{3} m(216)$ or $T_{d}^{2}$. That JCPDS card assigns the number of molecules per unit cell $(Z)$ to 2. Since the number of lattice points per unit cell for a facecentered cubic structure is 4 , this would make the number of

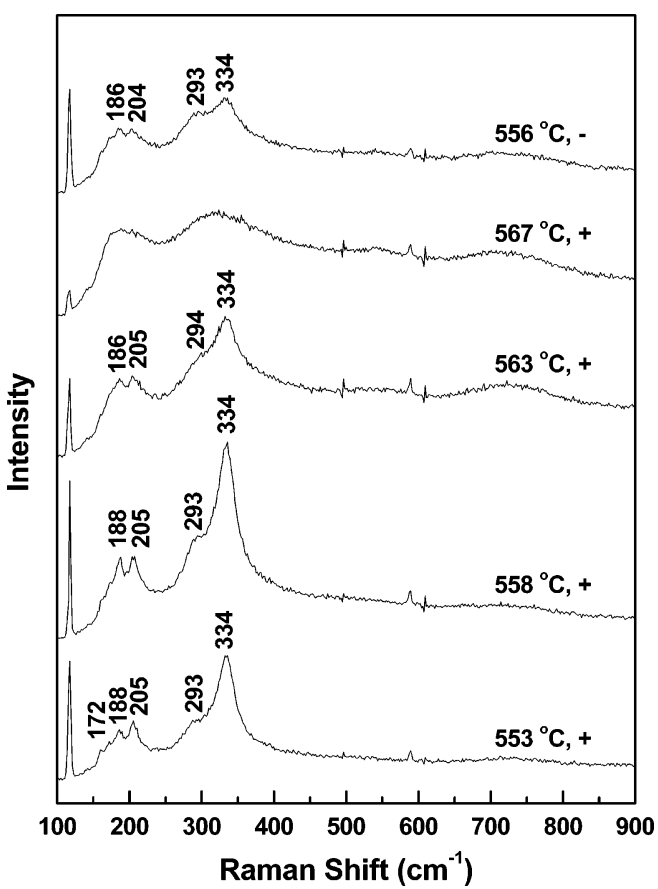

Figure 5. Raman spectra for $\mathrm{Ni}_{3} \mathrm{~S}_{2}$ near the temperature of transition from the low-temperature rhombohedral (heazlewoodite) phase to the high-temperature cubic phase. The symbol "+" indicates the spectrum was taken during the heating process, while the symbol "-" indicates the spectrum was taken during the cooling process. The extra peak at $\sim 120 \mathrm{~cm}^{-1}$ is due to stray light, while the peak at $589 \mathrm{~cm}^{-1}$ is due to adsorbed hydrogen. ${ }^{14}$

molecules per lattice point equal to 0.5 , which is hard to justify. By contrast, it has been proposed that the structure of the hightemperature cubic-phase $\mathrm{Ni}_{3} \mathrm{~S}_{2}$ has a defective antifluorite structure. ${ }^{18-20}$ In the authors' opinion, the later explanation is more reasonable. The real chemical formula for the hightemperature $\mathrm{Ni}_{3} \mathrm{~S}_{2}$ would thus be $\mathrm{Ni}_{4-\delta} \mathrm{S}_{2}{ }^{18}$ or, more precisely, $\mathrm{Ni}_{2-\delta} \mathrm{S} .{ }^{19,20}$ This change makes the total number of molecules per unit cell equal to 4 . The antifluorite structure has a space group of $F m 3 m(225)$ or $O_{h}^{5}$, for which $\Gamma_{\text {vib }}^{\text {Fluorite,crystal }}=\mathrm{F}_{1 \mathrm{u}}^{\mathrm{IR}}+$ $\mathrm{F}_{2 \mathrm{~g}}^{\mathrm{R}}$. Of these modes, only $\mathrm{F}_{2 \mathrm{~g}}$ is a Raman-active mode, ${ }^{8}$ which matches the observation of a broad peak at $\sim 320 \mathrm{~cm}^{-1}$ as in Figure 5. However, the broad nature of this peak makes the use of the Raman spectrum as a fingerprint for $\mathrm{Ni}_{3} \mathrm{~S}_{2}$ at temperatures greater than $565 \pm 5{ }^{\circ} \mathrm{C}$ less attractive; the presence of $\mathrm{Ni}_{3} \mathrm{~S}_{2}$ is hard to judge without cooling below the transition temperature to observe the more distinct heazlewoodite signal, but cooling the sample may not be desirable for some in situ measurements.

\section{Conclusions}

The Raman spectra for the low-temperature (heazlewoodite) phase and the high-temperature (cubic) phase of $\mathrm{Ni}_{3} \mathrm{~S}_{2}$ have been characterized using ex situ and in situ Raman spectroscopy at different temperatures in controlled atmospheres. The results were analyzed using factor group analysis and compared with the data in the literature. It was demonstrated that with in situ Raman, the difficulty of obtaining pure samples with the right phase in the complex $\mathrm{Ni}-\mathrm{S}$ system could be overcome and the spectra for nickel sulfides could be obtained with much higher credibility.

Acknowledgment. This work was supported by the U.S. DOE-NETL SECA Core Technology Program (Grant No. DEFC26-04NT42219) and DOE Office of Basic Energy Sciences, Catalysis Science Program (Grant No. DE-FG02-06ER15837). 


\section{References and Notes}

(1) Pomfret, M. B.; Owrutsky, J. C.; Walker, R. A. J. Phys. Chem. B 2006, 110, 17305

(2) Pomfret, M. B.; Owrutsky, J. C.; Walker, R. A. Anal. Chem. 2007 79, 2367.

(3) Cheng, Z.; Liu, M. Solid State Ionics 2007, 178, 925

(4) Ozkan, U. S.; Zhang, L.; Ni, S.; Moctezuma, E. Energy Fuels 1994, 8,830

(5) Zhu, X.; Li, J.; Wadsworth, M.; Woods, R. Electrochemical Kinetics of the Anodic Dissolution of Nickel Matte and Synthetic $\mathrm{Ni}_{3} \mathrm{~S}_{2}$. In Hydrometallurgy and Refining of Nickel and Cobalt, Proceedings of the 27th Annual Hydrometallurgy Meeting of CIM, Sudbury, Ontario, Canada, Aug. 17-20, 1997; Cooper, W. C., Mihaylov, I., Eds.; Canadian Institute of Mining, Metallurgy and Petroleum: Montreal, Quebec, 1997; p 153.

(6) Bishop, D. W.; Thomas, A. S.; Ray, A. S. Mater. Res. Bull. 2000 35,1123 .

(7) RRUFF Database of Raman spectra, X-ray Diffraction and Chemistry Data for Minerals. http://rruff.info/index.php. The University of Arizona.

(8) Fateley, W. G.; Dollish, F. R.; McDevitt, N. T.; Bentley, F. F. Infrared and Raman Selection Rules for Molecular and Lattice Vibrations: The Correlation Methods; John Wiley \& Sons: New York, 1972.
(9) Dietz, R. E.; Parisot, G. I.; Meixner, A. E. Phys. Rev. B 1971, 4, 2302

(10) Melendres, C. A.; Xu, S. J. Electrochem. Soc. 1984, 130, 2239

(11) Rosenqvist, T. J. Iron Steel Inst. 1954, 176, 37.

(12) Chase, M. W., Jr.; Davies, C. A.; Downey, J. R., Jr.; Frurip, D. J.; McDonald, R. A.; Syverud, A. N. JANAF Thermochemical Tables, 3rd ed.; American Institute of Physics: New York, 1986.

(13) Wang, J. H.; Cheng, Z.; Brédas, J.-L.; Liu, M. J. Chem. Phys. In press.

(14) Colpa, J. P.; Ketelaar, J. A. Mol. Phys. 1958, 1, 14.

(15) Dong, J.; Zha, S.; Liu, M. Study of Sulfur-Nickel Interactions Using Raman Spectroscopy. In Proceedings of the 9th International Symposium on Solid Oxide Fuel Cells; Singhal, S. C., Mizusaki, J., Eds.; The Electrochemical Society: Pennington, NJ, 2005; Vol. 2005-07, p 1284

(16) Dong, J.; Cheng, Z.; Zha, S.; Liu, M. J. Power Sources 2006, 156 , 461.

(17) Kullerud, G.; Yund, R. A. J. Petrol. 1962, 3, 126.

(18) Line, G.; Huber, M. Compt. Rend. 1963, 256, 3118.

(19) Stølen, S.; Grønvold, F.; Westrum, E. F.; Kolonin, G. R. J. Chem. Thermodyn. 1991, 23, 77 .

(20) Fjellvåg, H.; Andersen, A. Acta Chem. Scand. 1994, 48, 290. 